\title{
Recent Advances in the Diagnosis and Treatment of
} PURPURA HAMORRHAGICA

\author{
BY
}

\author{
BRUCE WILLIAMSON, M.D., \\ (From The Children's Hospital, Paddington Green.)
}

The introduction of splenectomy in the treatment of purpura hæmorrhagica by Kaznelson(1) of Prague in 1916 marks one of the most striking advances in the therapy of blood diseases of recent years. Up to date more than sixty cases have been operated upon. The results are so uniformly good that it appears to be only a matter of time before the disease is classified as curable by splenectomy. The results are comparable with those of splenic anæmia and acholuric jaundice.

It is worthy of note that despite the widespread recognition of this form of treatment both on the Continent and in America the beneficial results are little known in this country. In Britain so far only two cases(27) have been recorded in which splenectomy was performed. Both gave encouraging results. That the disease is by no means common cannot be denied, but from the writer's own observations during the past two years it appears to exist in this country in about the same incidence as elsewhere. The purpose of the present article is to call attention to this excellent clinical field which is practically unexplored.

The number of published cases is now sufficiently great to admit of a short survey of the subject in the light of the results obtained. A review of the abstract of recorded cases brings out some very important features in the ætiology of the disease without, however, indicating the causal factor, which still remains obscure.

\section{Results of Splenectomy.}

This operation is almost uniformly successful in alleviating the symptoms. Further time must elapse, however, before we can definitely assert that the relief is permanent. The few cases which possess a postoperative period worthy of any consideration appear to hold out promise of success. In the first case operated upon, seven years have elapsed between the date of operation and the last report. During this period the patient has remained free from all signs and symptoms of the disease (Case No. 1).

TABLE I.

\begin{tabular}{|c|c|c|c|}
\hline Splenectomy. & \multicolumn{3}{|c|}{ Results. } \\
\hline No. of Cases. & Well. & Improved. & Died. \\
\hline 58 & 50 & 2 & 6 \\
\hline
\end{tabular}

In the compiling of the various tables for statistical purposes only authenticated cases are considered. Reference to the abstract (see page 8) will find several cases in which the diagnosis of purpura hæmorrhagica cannot be admitted owing to the presence of other morbid processes. These cases 
are examples of seconclary purpura with hæmorrhages and as such are rightly excluded.

The results set out in Table I. are very striking in view of the severity of the disease, its hæmorrhagic nature and the considerable risk involved in the operation.

Under the category " Well " we find fifty cases. The average duration of the post-operative period of this group is just under two years. It will be understood that the term " well " is employed in the sense that the patient is enjoying an active life and is no longer subject to hæmorrhages. The occurrence of slight hæmorrhage during the convalescent period is discounted as of no moment. In the great majority of cases in this category the recovery is complete. In a few cases, however, the purpuric manifestations have persisted in a minor degrce for some time after the operation. Kaznelson ${ }^{(2)}$ states in reference to his last case " that the effect of the surgical treatment in this case was to transform purpura hæmorrhagica into purpura simplex."

Under the category "Improved" there are but two cases, and little information is available beyond the statement that the severity of the disease has been somewhat abated.

\section{Mortality.}

The present series of records includes six cases which terminated fatally; a mortality of 6 in 58 .

At first sight this figure hardly appears to warrant an optimistic outlook for the new treatment. The mortality from the disease itself is probably little more than ten per cent., though it is diflicult to assess any figure, for no, reliable statistics exist. An analysis of the cases reveals interesting information.

As will be pointed out later, the diagnosis of the condition is only certain where the disease is chronic. Of the six fatal cases three only fulfil this proviso. Now of these three chronic cases the fatal result in two instances appears to be directly associated with the risks of operation and not with the disease itself. We are thus left with only a single instance of cleath following operation in an authentic case in a series of fifty-eight cases.

The following list of fatal cases is taken from the abstract :-

TABLE II.

\begin{tabular}{|c|c|c|c|c|c|}
\hline $\begin{array}{l}\text { Case } \\
\text { No. }\end{array}$ & Sex. & $\begin{array}{l}\text { Age at } \\
\text { onset. }\end{array}$ & Duration. & $\begin{array}{l}\text { Main Site of } \\
\text { Hæmorrhage. }\end{array}$ & Remarks. \\
\hline 3 & F. & 20 & $7 / 12$ years & Nose & Myocardial hæmorrhage. \\
\hline 17 & $\mathrm{~F}$. & 9 & 12 years & Uterus & $\begin{array}{l}\text { Subphrenic abscess on } 29 \text { th } \\
\text { day. }\end{array}$ \\
\hline 26 & M. & 29 & 4 days & Bowel & \\
\hline 34 & F. & 16 & 4 days & Uterus & \\
\hline 41 & F. & 12 & 4 years & Nose & $\begin{array}{c}\text { Accident, hæmorrhage at } \\
\text { operation. Death } 6 \\
\text { hours post-operation. }\end{array}$ \\
\hline 65 & M. & 45 & Very short & & \\
\hline
\end{tabular}


Age at (onset.

Some Aetiological Factors.

The disease is essentially one of early youth. $\Lambda \mathrm{n}$ analyșis of the abstract clearly establishes this. In the youngest case recorded the onset of the disease occurred in the 3rd year. The commonest age for the disease to manifest itself is about the 5th year; thereafter it steadily declines up to the 15 th year. Later the incidence of onset falls rapidly and the disease rarely commences after the age of thirty years.

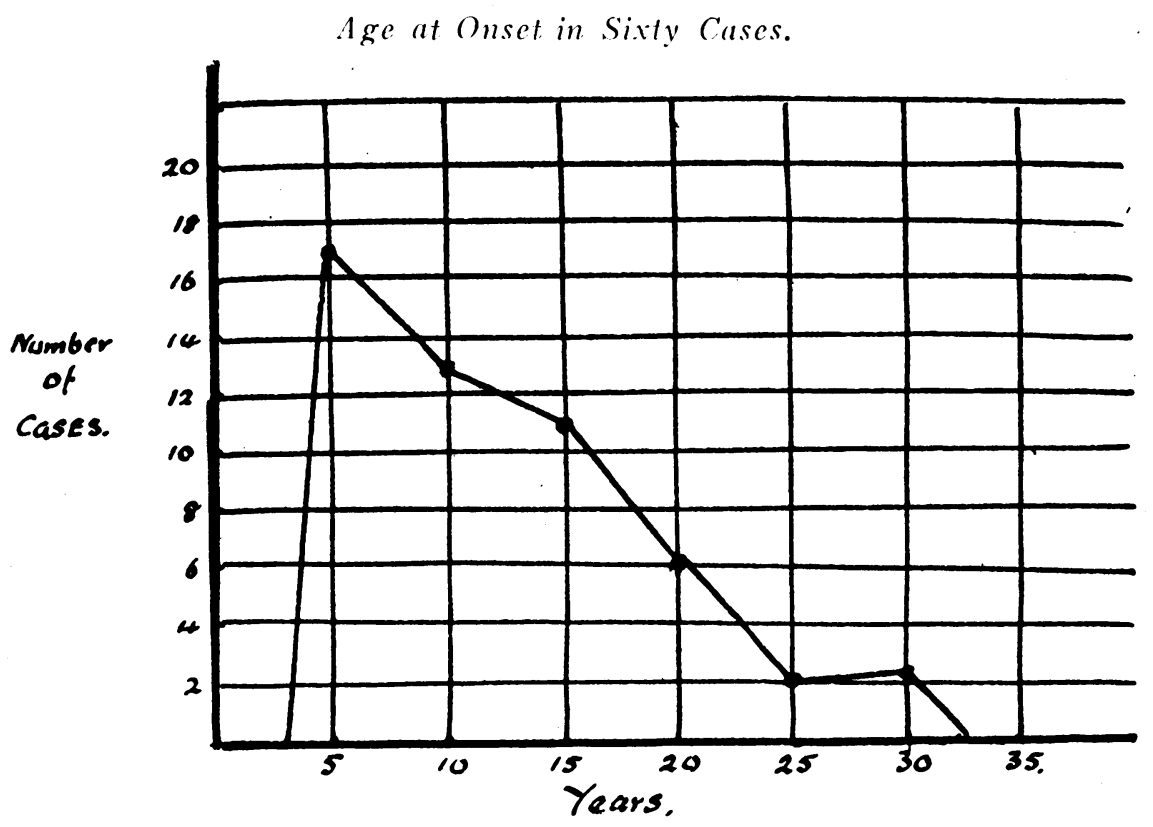

Sex.

Another striking feature is the preponderance of the condition amongst females. Out of a total of fifty-eight authentic cases forty-four were females and fourteen males-a ratio greater than 3 to 1 . Menstruation does not appear to be a deciding factor in the disparity of the incidences of the disease in the two sexes, for the preponderance is clearly established before the age of puberty.

\section{Duration.}

The longest duration of the disease recorded in the present series is thirty years.

In the majority of cases the condition appears to be chronic. The onset may be acute, but as a rule it is insidious. Remissions are a common feature in most cases. During the period of remission the patient may be frec from all signs of a hæmorrhagic tendency. More commonly, however, there is only a cessation of external hæmorrhages, and usually one or more features of the condition persist in the skin and mucous membranes, i.e., a state of purpura simplex is more or less persistent.

The blood changes which are so prominent a feature of the discase participate in these fluctuations. 
The existence of an acute form of the condition is a matter of uncertainty. The evidence in support of such a type is extremely meagre. The only published record of cases with a single attack are those which have come to operation, and it is a moot point as to whether these cases would not have pursued the usual chronic course had they been left untreated.

Dr. G. A. Sutherland has informed the writer that he had met with cases in young subjects which presented all the clinical and blood features of purpura hæmorrhagica without a history of a previous attack. These cases have all recovered from their first attack unaided by treatment, apart from rest in bed. It will be of interest to note whether these subjects develop further attacks.

\section{Forms of Hamorrhage.}

Hæmorrhage may occur in any part of the body. The nose and the uterus are the sites of major hæmorrhage and practically all cases fall into two groups :-

1. Those with epistaxis as the main feature.

2. Those in which uterine hæmorrhage predominates.

In females it appears to be the regular course for the disease to begin in childhood with recurrent epistaxis. Where this is mild no advice is sought. At the onset of menstruation epistaxis usually becomes less frequent and of minor import. The main site of hæmorrhage is then transferred to the uterus. Menorrhagia occurs and this, not infrequently, passes on to intractable metrorrhagia. This type of case constitutes the gravest form of the disease.

TABLE III.

\begin{tabular}{lccc|c}
\hline \multicolumn{3}{c|}{$\begin{array}{c}\text { Sites of } \\
\text { Hæmorrhage. }\end{array}$} & & $\begin{array}{c}\text { Incidence in } \\
\text { 54 Cases. }\end{array}$ \\
Gums & $\ldots$ & $\ldots$ & $\ldots$ & 43 \\
Nose ... & $\ldots$ & $\ldots$ & $\ldots$ & 30 \\
Uterus & $\ldots$ & $\ldots$ & $\ldots$ & 24 \\
Urinary & Tract & $\ldots$ & $\ldots$ & 2 \\
Brain & $\ldots$ & $\ldots$ & $\ldots$ & 2 \\
Bowel & $\ldots$ & $\ldots$ & $\ldots$ & 2 \\
$\begin{array}{l}\text { Skin :- } \\
\text { Petechiæ and }\end{array}$ \\
\hline
\end{tabular}

The minor hæmorrhages, petechiæ and ecchymoses, are present in all cases. Bleeding from the gum is so commonly found as to be of some diagnostic value. It consists of a continuous ooze from the crest of the gum which defies all local treatment, at times the loss of blood is severe and considerable. 
Melæna is by no means an uncommon finding. This is usually due to swallowed blood from the nose and mouth, and rarely is it due to hæmorrhage from the bowel. Hæmorrhages from the bowel may, however, occur.

Several cases are recorded where intracranial hæmorrhage has occurred as manifested by temporary paralysis. $\Lambda$ fatal case of intraventricular hamorrhage is recorded by Pereyra(15).

Other less common sites are the urinary tract, joints, muscles and retina.

\section{Diagnosis.}

Prior to the work of Frank and Kaznelson the term purpura hamorrhagica was applied with much ambiguity. $\Lambda$ recapitulation of the various conditions which received the title of purpura hæmorrhagica would serve no useful purpose here other than to indicate the desirability of a recognised definition of the term.

Since the introduction of splenectomy as a form of treatment several new titles for the condition are found in the literature, such as thrombopenic purpura hæmorrhagica, essential thrombocytopenic purpura hæmorrhagica, and even essential thrombocytopenia. These titles have served a useful purpose in focussing the attention of clinicians on the necessity for an accurate cliagnosis in view of the gravity of the operative treatment. With the increasing recognition of the disease the present tendency is to return to the original title of Werlhof, namely, purpura hæmorrhagica. He applied this to an idiopathic condition in which there were purpuric manifestations on the surfaces of the body accompanied by hæmorrhage from the mucous membranes. His definition holds good to-day so far as it goes, but now certain features in the blood must be essentially present before the term purpura hæmorrhagica is applied.

A survey of the published cases emphasises the necessity of a rigici acceptance of the modern interpretation of the term purpura hæmorrhagica before splenectomy is undertaken. To apply this method of treatment to cases which present other features in addition to those of purpura hæmorrhagica is to enter the field of experimentation, and it should be clearly recognised as such, lest the undoubted value of splenectomy in purpura hæmorrhagica be called into question.

Briefly the points of diagnosis are as follows :-

1. Purpuric manifestations in the skin and mucous membranes, i.e., petechiæ and ecchymoses.

2. . External hæmorrhage from the mucous membrane.

3. It is a primary disease.

4. There must be an entire absence of significant signs and symptoms apart from :-

(a) Those associated with hæmorrhage.

(b) The resultant anæmia, which is essentially of the chlorotic type.

(c) The enlargement of the spleen which may or may not be palpable.

5. It is a disease of early life running a chronic course.

6. Negative family history.

7. The blood shows the following features :-

(a) Considerable reduction in the number of blood-platelets.

(b) A non-retractile clot.

(c) Prolonged bleeding-time with a normal coagulation time. 
It must be pointed out that the above changes in the blood are not solely confined to purpura hæmorrhagica. They may be present wholly or in part in other conditions. It is not uncommon to encounter them in the various blood dyscrasias such as pernicious anæmia and the leukæmias. Apart from blood discases they are liable to be present in any condition complicated $\mathrm{by}$ a secondary purpuric eruption. They are, in fact, only of significance when they stand alone in a subject as a primary condition. Case No. 55 in the abstract provides valuable illustration of the relative unimportance of the blood changes per se in the diagnosis of purpura hæmorrhagica. This case presented a blood condition typical of purpura hæmorrhagica, but in addition the blood picture indicated a marked myelogenous and erythroblastic reaction in the bone marrow. This case terminated fatally. The diagnosis appears to be myelogenous leukæmia.

It is obvious from a study of the recorded cases that the greatest difficulty in diagnosis lies in discriminating between primary purpura hæmorrhagica and secondary purpura with hæmorrhages. Each case requires prolonged investigation before one can be reasonably certain that the hæmorrhagic features are primary and not secondary to other morbid processes. In many cases time alone reill rezeal the true nature of the condition present.

During the first attack of the disease it is quite impossible to be certain that the condition is not secondary. Where the onset of purpura hæmorrhagica is acute the clinical picture is very close to that of the hamorrhagic forms of some of the exanthemata. Unfortunately the blood changes are common to both conditions and afford no guide to diagnosis.

The problem is clearly reflected by the results of operation in the so-called acute form of the disease. Three cases have come to operation within four days of the onset and all have ended fatally. At autopsy two showed no lesion to which the condition could be attributed, the third showed extensiva tuberculosis. Against these we can find only one case operated upon during the first attack which recovered. The inference is clear-operation during the first attack of the disease is strongly contraindicated both on account of the uncertainty of diagnosis at this stage of the disease and because of the unfavourable results recorded.

The paucity of recorded cases treated by operation in this country seems to indicate that the disease is not being recognised. Contrary to the general conception, the disease, in the majority of instances, is not very evident at first sight. The skin manifestations are not as a rule very intense, in many cases they consist of a few scattered petechiæ in the region of the upper thorax and neck. The sites of any constricting band such as the collar and waist-band, may exhibit a few pinpoint hæmorrhages under the skin. Their presence should excite suspicion and a careful and complete physical examination with serious enquiry into the past history may lead to the recognition of the obscure cases.

Enquiry into those anomalous cases of recurring epistaxis which not infrequently present themselves at casualty departments would undoubtedly lead to a more frequent recognition of the condition.

Another class of case which could be readily missed is the one which comes to the gynæcologist for severe menorrhagia or metrorrhagia. Almost half the number of cases which have come to operation are of this class. Where the female subject has reached the age of puberty uterine hæmorrhage is the classical form of the disease. All cases of intractable uterine hæmorrhage not due to a local cause should be subjected to a complete 
physical examination. The features in the blood characteristic of purpura hæmorrhagica should be looked for, and the past history carefully studied.

A third source of enquiry lies in those cases of so-called atypical hæmophilia. The diagnosis of hæmophilia is often too readily made despite the absence of some of the main features of the condition. Where the clinical picture does not conform to the requirements laid down by Bulloch and Fildes(38) in their classical monograph the diagnosis of hæmophilia may be viewed with suspicion. The existence of hæmophilia in females has never been accepted notwithstanding several reported cases. A negative family history in any case exhibiting a hæmorrhagic diathesis strongly suggests the possibility of the case being one of purpura hæmorrhagica.

The writer has met one case which for eight years was considered one of hæmophilia despite a completely negative family history. Complete investigation revealed a perfect example of purpura hæmorrhagica.

Happily the two conditions are readily distinguishable notwithstanding a superficial resemblance to each other. The points in the differential diagnosis are as follows:-

\begin{tabular}{lcc|cc}
\hline & & & $\begin{array}{c}\text { Purpura } \\
\text { Hæmorrhagica. }\end{array}$ & Hæmophilia. \\
\cline { 3 - 4 } Sex & $\ldots$ & $\ldots$ & Either & Males only \\
Family History & $\ldots$ & Negative & Positive \\
Coagulation Time... & Normal & Prolonged \\
Bleeding Time & $\ldots$ & Prolonged & Normal \\
Blood Platelets & $\ldots$ & Diminished & Normal \\
Clot Retraction & $\ldots$ & Absent & Normal \\
\hline
\end{tabular}

\section{Conclusions.}

A study of the published cases of purpura hamorrhagica treated by splenectomy justifies the acceptance of this method of treatment. But excellent as are the results of spenectomy, each case requires to be considerea on its own merits. Where the disease is mild and causes no great inconvenience to the patient, splenectomy is not justified.

The operation should be reserved for chronic cases which fall into two groups :-

(i.) Where chronicity with severity so interferes with the normal life of the subject that a state of chronic invalidism is established.

(ii.) Where the severity of the hamorrhages and the frequency of its occurrence constitute a real clanger to the life of the patient. 


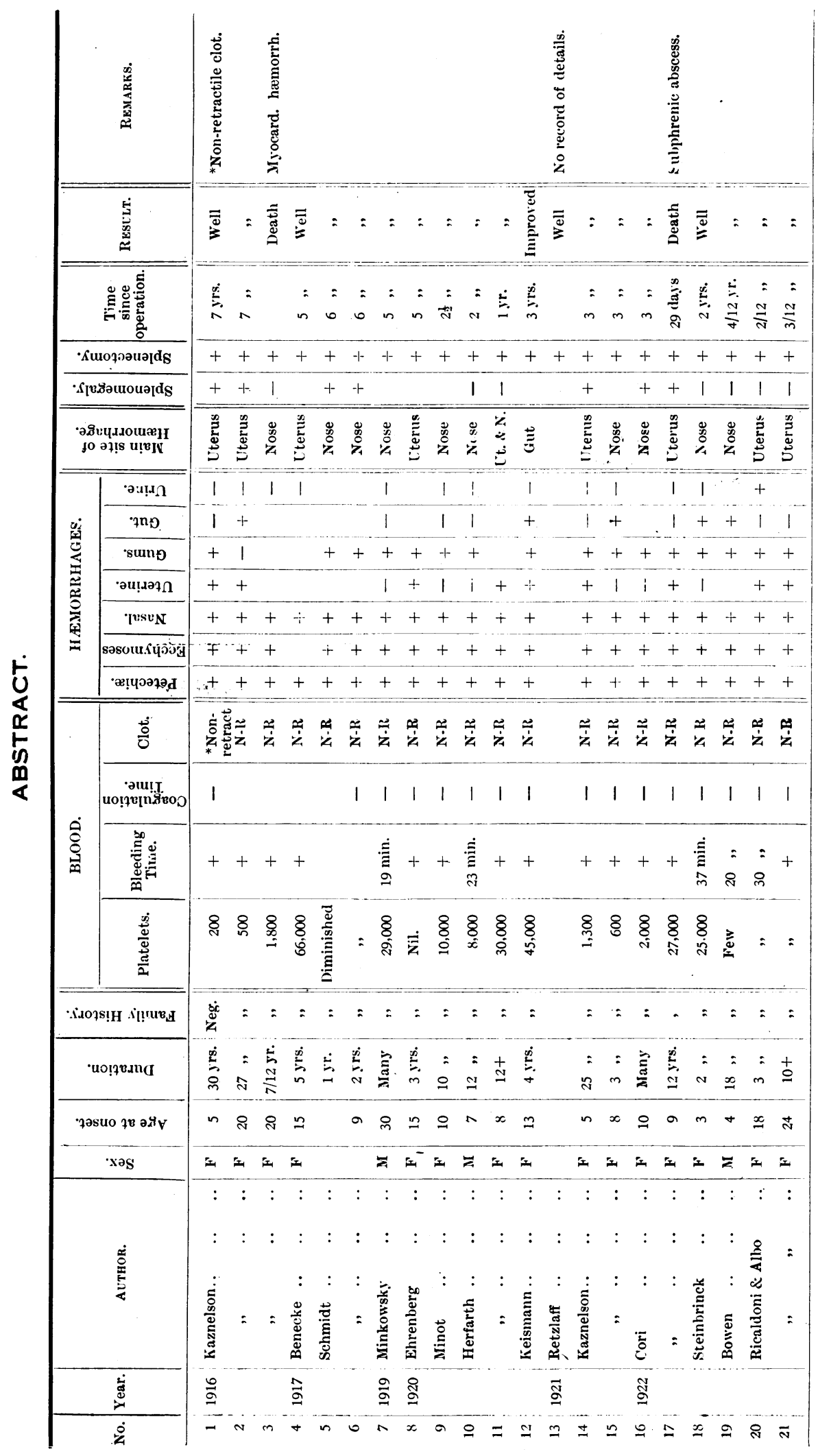

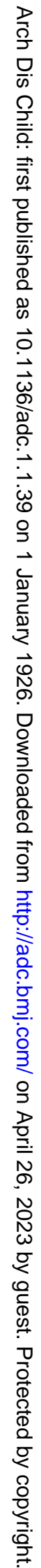




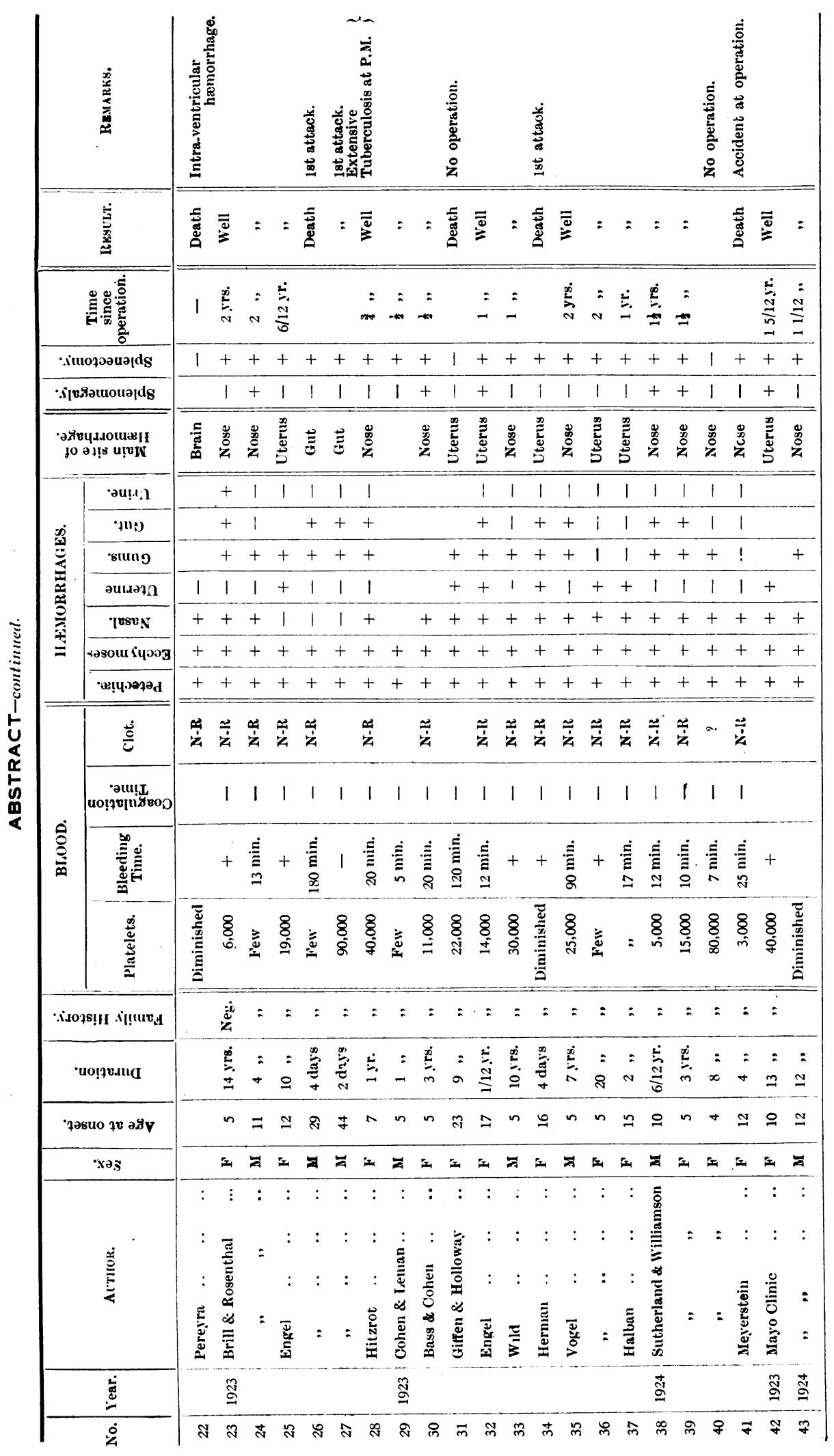




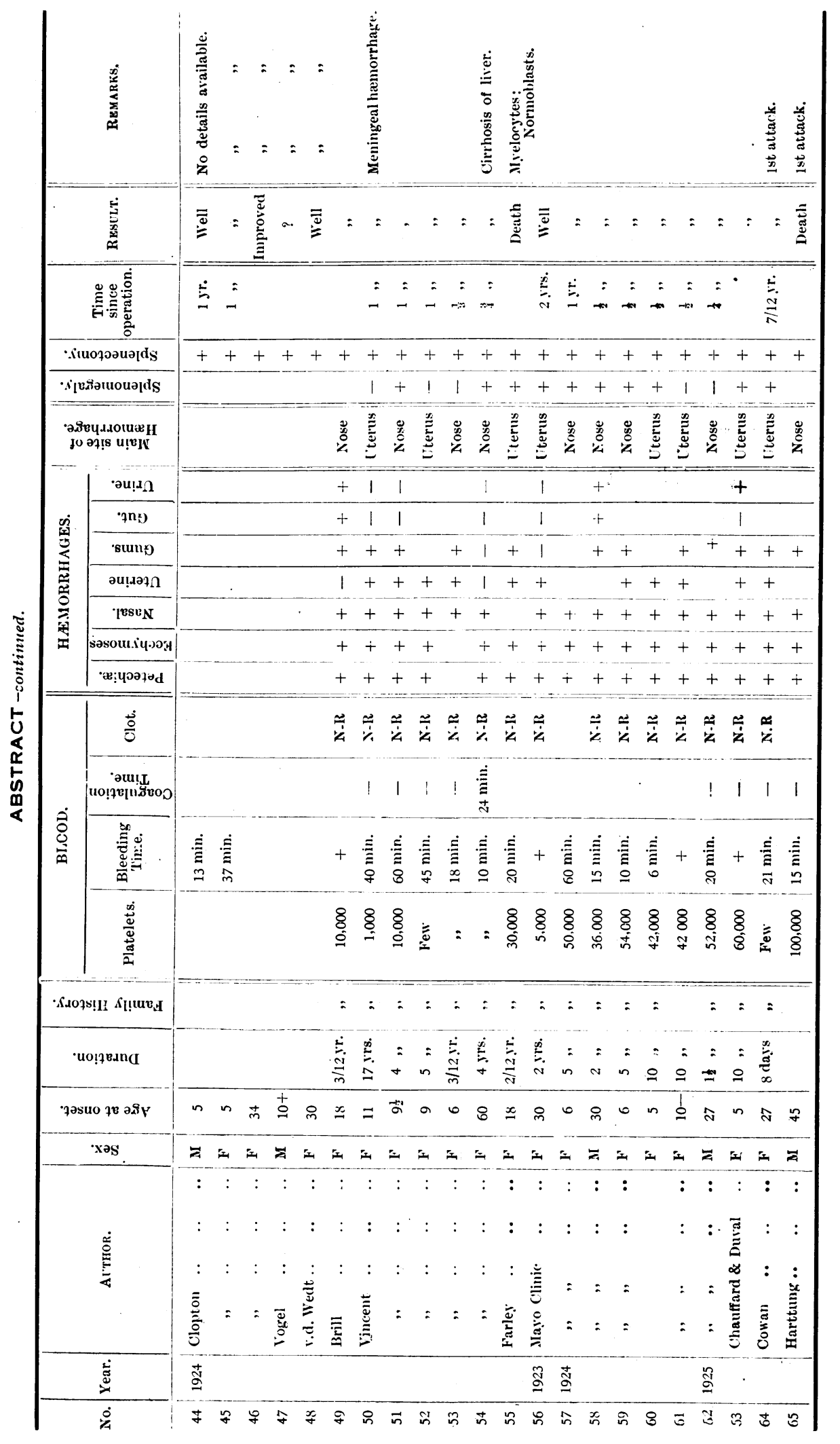

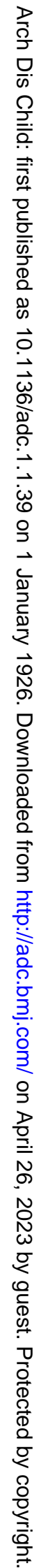


BIBLIOGRAYHY.

1. Kaznelson: Wien. Klin. Wchnschr., 29, 1916.

2. Kaznelson: Med. Klin., xvii., 974, 1921.

3. Benecke: Therapie der Gegenwert, xxx., 959, 1917.

4. Schmidt: Hien. Kiin. Wchnschr., xxx., 1917.

5. Minkowslii : Med. Klin., No. 50, 51, 1919.

b. Ehrenberg: Monatschr. f. Geburt u. Gyn., li., 99, 1920.

7. Eylenburg : Cited by Brill, Ref. No. 17.

8. Minot: Trans. Ass. of Am. Phys., May, 1923.

9. Herfarth : Bruns. Beitr. z. Klin. Chirurg., 128-282.

10. Keismann : Med. Klin., Nr. 3, 72, 1921.

i1. Cori: Ztschr. f. Klin. Med., xciv., 356, 1922.

12. Steinbrinck: Ztschr. f. Klin. Med., xciv., 447, 1922.

i3. Bowen: Buffalo Gen. Hosp. Bull., Jan. 1923.

14. Ricaldoni and Albo: Bull. et Mém. de la Soc. Méd. de's Hôp. de Paris 13, 10 April, 1924.

15. Pereyra: Arch. Lat. Im. de Ped., xvi., 1922.

16. Brill : Internat. Clinic, 34, Mch., 1924.

17. Brill and Rosenthal: Trans. Ass. of Am. Phys., May, 1923.

18. Engel: Arch. Klin. Chir. v. Langenbeck, 129, 1924.

19. Hitzrot: Annals of Surg., 1923.

20. Cohen and Leman: Surg. Gyn. and Obstet., 38-596, 1924.

21. Bass and Cohen : Am. J. Dis. of Child., 47-332, 1924.

22. Giffen and Holloway: Med. Chir. of N. Am., July, 1923.

23. Mayo, W. J.: Bost. M. and S. J., Jan. 3, 1924, also J. Am. Me'd. Ass., vol. 83, 11, 1924.

24. Wild: Mitteil a.d. Grenzgeb., 37, 201, 1923.

25. Herman : Cited by Engel. Ref. 18.

26. Halban : Arch. f. Gynak., 118-229.

27. Sutherland and Williamson: The Lancet, Feb. 14, 1925.

28. Vogel : Cited by Engel, Ref. 18, also Dtsch. Zcitschr. f. Chir., 180, 80, 1923.

29. V. d. Wedt : Miinch. Med. Schschr. (Proceedings No. 120, 1924.)

30. Meyerstein : Zeit. f. Kind., 38, 11, 1924.

31. Clopton : J. Am. Med. Ass., Jan. 3, 1925.

32. Chauffard and Duval: Bull. et Mém. de la Soc. Nut. de Chir., I'aris, 1925, li., 513.

33. Vincent : Boston Med. and S. J., 193, 5, 191.

34. Farley: $A m$. J. Med. Sci., clxx., 1, 640.

35. Cowan: Med. J. of Austral, vii., No. 10.

36. Giffen and Holloway: Am. J. Med. Sci., clxx., 2, 641.

37. Hartung: Deut. Zeit. f. Chir., 1925, June, p. 91.

38. Bulloch and Fildes: Hecmophilia, Dulan, London, 1911. 